\title{
Patient acceptability of genotypic testing for hemochromatosis in primary care
}

Roger T. Anderson, $P h D^{1}$, Nancy Press, $P h D^{2}$, Diane C. Tucker, $P h D^{3}$, Beverly M. Snively, $P h D^{1}$, Lari Wenzel, $P h D^{4}$, Shellie D. Ellis, MA ${ }^{1}$, Mark A. Hall, JD ${ }^{1}$, Ann P. Walker, $M A^{5}$, Elizabeth J. Thomson, $R N, P h D^{6}$, Ometha Lewis-Jack, $P h D^{7}$, and Ronald T. Acton, $P h D^{8}$

\begin{abstract}
Purpose: Genetic screening can enable timely detection and treatment of hereditary hemochromatosis (HH). Little is known about patient acceptability of DNA testing as compared to conventional phenotypic testing. Methods: Within the HEIRS Study, a large primary-care screening study of $\mathrm{HH}$ and iron overload, we randomly assigned participants to receive brief information on either $\mathrm{HH}$ genotypic or phenotypic testing, and assessed the willingness to accept this test. The study was designed to recruit an equal number of African Americans and Caucasians. Results: A total of 2500 participants were recruited from waiting rooms of primary care practices; 2165 participants who self-identified as African Americans and Caucasians were included in the analyses. Overall, 56\% had accepted a genotypic test versus 58\% for a phenotypic test. Adjusting for Field Center (FC), age, gender, race, educational attainment, global health rating, and knowledge of the test, the odds ratio of accepting a genotypic versus phenotypic test was $0.85(95 \% \mathrm{Cl}: 0.71,1.02 ; P=0.078)$. Characteristics associated with test acceptance were age 45-64 years, female gender, Caucasian race, self-rated health less than "very good", and knowledge of the test. Test acceptance was associated with interest in knowing more about health (81\%) and in helping family members (71\%). Refusal reasons included a need to talk with a doctor (44\%), concern about privacy (32\%), and dislike of blood drawing (29\%). Conclusion: In this diverse sample of primary care patients, stated acceptance of genotypic testing for $\mathrm{HH}$ mutations was similar to phenotypic testing for blood iron. Patient education regarding the nature of test, importance of disease detection, and privacy protection appear to be essential for achieving high rates of screening participation. Genet Med 2005:7(8):557-563.
\end{abstract}

\section{INTRODUCTION}

The development of genetic screening provides new tools to detect risk for an expanding array of diseases, promising more timely, and effective treatment. ${ }^{1,2}$ There is some concern that individuals who could benefit from genetic risk assessment might perceive this information as anxiety provoking, and opt out of screening. ${ }^{3-5}$ The results of studies on the ethical, legal, and social implications receiving information through a genetic test about one's susceptibility to disease are mixed. ${ }^{6,7}$ Many studies show marked anticipatory anxiety among those

\footnotetext{
From the ${ }^{1}$ Department of Public Health Sciences, Wake Forest University School of Medicine, Winston-Salem, NC; ${ }^{2}$ Kaiser Permanente Center for Health Research, Portland, Oregon; ${ }^{3}$ Department of Psychology, University of Alabama at Birmingham; ${ }^{4}$ Epidemiology Division, Department of Medicine, University of California, Irvine, California; ${ }^{5}$ Division of Human Genetics, Department of Pediatrics, University of California, Irvine, California; ${ }^{6}$ National Human Genome Research Institute, Bethesda, Maryland; ${ }^{7}$ Department of Psychology, Howard University, Washington DC; ${ }^{8}$ Department of Microbiology, University of Alabama at Birmingham.

Roger T. Anderson, PhD, Department of Public Health Sciences, Wake Forest University School of Medicine, Medical Center Blvd, Winston-Salem, NC 27157.

Received: May 11, 2005

Accepted: June 7, 2005
}

DOI: 10.1097/01.GIM.0000177531.53338.65 awaiting testing, ${ }^{8-12}$ albeit far fewer find evidence of significant psychological symptoms or emotional upset after testing, even among those found to be carriers. ${ }^{9,13-16}$

Although there is a growing need for research in this area, much of the research regarding the ethical, legal, and social implications (ELSI) of receiving genetic information about one's susceptibility to disease involves testing selected individuals for familial cancer syndromes or other dominantly inherited diseases where disease risk is generally suspected before testing is ever discussed or offered. ${ }^{10,11,17-22}$ Much less research has been conducted on general population screening for a disease for which individuals have little reason to suspect they are at risk and where both phenotypic and genotypic tests are available. In addition, few studies have collected information on willingness to be screened and reasons for acceptance or refusal of testing.

Hemochromatosis $(\mathrm{HH})$ is one of the most prevalent autosomal recessive genetic disorders in some populations, and despite widespread public familiarity, occurs in $0.3 \%$ to $0.5 \%$ of Caucasians of North-Western European descent. ${ }^{23}$ If untreated, $\mathrm{HH}$ and iron overload may cause increased absorption and tissue deposition of dietary iron that may lead to organ toxicity ${ }^{24,25}$ and increased risk for hepatic cirrhosis, primary liver cancer, endocrine disorders, arthropathy, cardiomyopathy, and reduced longevity. Timely removal of iron can prevent 
all complications of this disorder. ${ }^{26}$ Because causative genetic defects have been identified and an effective treatment exists via phlebotomy, some researchers have proposed widespread genetic screening for $\mathrm{HH} .24,25,27$

Risk for iron overload may be assessed using either current clinical biochemical laboratory assays or by testing for mutations in HFE (responsible for most cases of $\mathrm{HH})^{28}$ or other genes. ${ }^{29}$ Thus, there is need to evaluate the two strategies to compare their acceptability to the public at large or to particular population groups. A public health strategy based on genetic screening could be ineffective for $\mathrm{HH}$, and perhaps for other conditions for which genetic tests become available, if a sizable proportion of people are averse to genetic testing. Past studies have assessed the acceptability of genetic screening for $\mathrm{HH},{ }^{30,31}$ but these studies are applicable only to the countries in which they were conducted and have not assessed participants' behavior to see if it matched their stated intentions.

In this study, we report patients' level of interest in undergoing testing for $\mathrm{HH}$ depending on whether they were offered a genetic test or a clinical biochemical test and provide data on what proportion actually underwent genetic testing. We hypothesized that acceptance of genotyping would be lower than that for phenotyping, reflecting concerns about use of genetic information and privacy. We also explore whether African Americans would be more cautious about genetic testing than Caucasians, reflecting a history of societal bias based upon inherited characteristics and the legacy of misuse of the concept of race in scientific research. ${ }^{32}$

\section{MATERIALS}

This study was conducted as part of a larger multisite observational cohort study, the Hemochromatosis Iron Overload Study (HEIRS) that sought to evaluate the prevalence, determinants, and clinical, personal, and societal impact of $\mathrm{HH}$ and iron overload in a multiethnic primary care sample of 101,168 screened adults, ages 25 years and older. ${ }^{33}$ The data reported here were collected in three of the five Field Centers (FCs) using a randomized design. Two test conditions were created that systematically varied information about the type of test hypothetically being offered. Institutional review board approval to obtain verbal consent and to conduct the protocol was obtained by each FC and the HEIRS Coordinating Center.

Participants were recruited in the waiting areas of public and private primary care offices and ambulatory clinics affiliated with or contracted by HEIRS FCs at the University of Alabama, Birmingham (UAB), University of California, Irvine (UCI), and Howard University (HU). These sites were chosen because their clinical networks served patients from diverse socioeconomic backgrounds. African American patients were recruited at $\mathrm{UAB}$ and $\mathrm{HU}$, and Caucasian patients were recruited at $\mathrm{UAB}$ and UCI.

Participants were randomly assigned study packets containing descriptions of either phenotypic or genotypic testing for $\mathrm{HH}$ and relevant study questionnaires were ordered and numbered via a predetermined block randomization. Study staff were blinded to group assignment. Each clinic had specific goals to enroll adult, English-speaking Caucasian (UCI and $\mathrm{UAB}$ ) or African American (Howard and UAB) participants 25 years of age or older, consistent with HEIRS age eligibility criteria. Any patient or visitor in waiting areas of the study sites who appeared to belong to the FC's race/ethnicity target groups and confirmed their age eligibility was invited to participate. Upon patient's verbal consent, study staff gave the participant the next randomly ordered sealed packet containing identical information about hemochromatosis and one of the two following screening test descriptions:

"A blood iron test is now available for hemochromatosis. For this test, a small sample of your blood will be taken to measure the amount of iron in your body. If the blood test shows that your iron is not at a safe level, your doctor will discuss this with you and do some additional tests."

"A genetic test is now available for risk of hemochromatosis. This test looks to see if you have the type of gene that increases your risk for iron overload. A small sample of your blood will be taken so that your genes can be examined. If this test shows that you carry one of the genes, this does not necessarily mean that you have too much iron in you body. Your doctor will have to discuss your results with you and do some additional medical tests to see if your iron levels are unsafe."

On their initial self-administered questionnaire, participants were asked whether they would be willing to take the test described in their packet if it were offered at the clinic. Based on their response ("yes" or "no"), they were instructed to complete a subsequent questionnaire about their reasons for either accepting or declining (developed by study investigators), and information on their age, gender, educational status, ethnicity and/or race, attitudes about family benefit, perceived usefulness of the test result information, health concerns, positive or negative consequences of having iron overload, and recognition of the type of test offered. The participant was classified as correctly identifying an offer of a clinical biochemical blood test (phenotypic test) if he/she reported being offered "a blood test" only, and classified as correctly identifying an offer for a genotype test if he/she reported being offered either "a gene test," or if both "gene test" and "blood tests" were checked. Perceived health status was assessed with the Medical Outcomes Study (MOS) general health scale. ${ }^{34,35}$ After completing the survey, the participant was instructed to place the materials in the envelope provided and hand it to the study administrator.

Finally, upon receiving the participant's completed study packet, the questionnaire administrator, blinded to the acceptability survey response (i.e., either accept or decline the hypothetical test), initiated the standard HEIRS recruitment procedures whereby the HEIRS screening study was introduced and the patient verbally invited to join the study. Those who agreed to enroll in HEIRS were immediately given an informed consent for review, discussion, and signature. For the purposes of the present study, the administrator recorded the final disposition of each acceptability study participant as either "enrolled" or "not enrolled" in HEIRS based upon completion of an informed consent to participate. For the latter, the HEIRS 
study screening was conducted on-site before discharge from the patient visit.

\section{Statistical analyses}

Potential predictors of willingness to take the diagnostic test were evaluated in a multiple logistic regression model. Predictors included type of test (phenotypic vs. genetic test), gender, age group $(<45,45-64$, and $65+$ years $)$, race/ethnicity-FC group (UCI Caucasian, UAB Caucasian, UAB African American, and HU African American), educational status ( $\leq$ high school and $>$ high school), MOS general health score (divided by 10), and knowledge of the type of test (correct, incorrect or don't know, and missing). Interaction between type of test and race/ethnicity-FC was evaluated after adjusting for all other potential predictors in the model. Three pair-wise comparisons were evaluated without correction for multiplicity in the full model between race/ethnicity-FC groups: UCI Caucasian versus UAB Caucasian, UAB African American versus HU African American, and UAB Caucasian versus UAB African American. All analyses were performed using SAS Statistical Software (version 8, SAS Institute, Cary, North Carolina). Confidence intervals are reported at the $95 \%$ level. $P \leq 0.05$ was considered statistically significant.

\section{RESULTS}

Table 1 shows the demographic characteristics of the study participants. A total of 2500 participants were recruited among the study sites; of these, 2165 met final study eligibility by selfidentifying as either African American or Caucasian without other race/ethnicities listed. Randomized to the genotype and phenotype test descriptions were 559 and 538 Caucasians, and 538 and 530 African Americans, respectively. The percentages of participants accepting a hypothetical $\mathrm{HH}$ test by type of test, and participant's gender, age, race/ethnicity, FC, educational attainment, and knowledge of the test offered are shown in Table 2. The proportion in each group who said they would accept the hypothetical test described was similar. Females were similar to males in stated acceptance of genetic testing, but were more likely than males to accept a phenotypic test. Overall differences in stated acceptability were found for the FC and race/ethnicity groups for both types of tests. The highest rates of stated test acceptance were found among Caucasians at UCI and UAB (ranging from $57.8 \%$ to $67.4 \%$ ), while African Americans at UAB had the lowest acceptance (44.0\% and $49.4 \%$ ). Participants with at least some college education were somewhat more willing to accept a phenotypic test of body iron stores than those with who had completed only high school or less, but educational attainment made little difference in the acceptability of a genotypic test. Having correct knowledge of type of test was significantly associated with higher acceptance of the genetic test, and was associated with acceptance of the phenotypic test as well.

Table 3 presents the main effects model of overall stated acceptance of $\mathrm{HH} /$ iron overload testing from the multivariable logistic regression analysis. Of primary interest, when adjusted for all model covariates, the odds ratio of accepting a hypothetical offer of a genetic versus a phenotypic test was 0.85 ( 0.71 to $1.02, P=0.078)$. Interactions of test type with other model covariates (e.g., age group, gender, race/FC, health status) were

Table 1

Demographic characteristics of the sample

\begin{tabular}{|c|c|c|c|c|c|}
\hline \multirow[b]{2}{*}{ Field center } & \multicolumn{2}{|c|}{ African American } & \multicolumn{2}{|c|}{ Caucasian } & \multirow[b]{2}{*}{ Overall } \\
\hline & UAB & Howard & UAB & UCI & \\
\hline $\mathrm{N}$ & 523 & 545 & 524 & 573 & 2165 \\
\hline \multicolumn{6}{|l|}{ Race/ethnicity } \\
\hline African American only & 523 & 545 & NA & NA & $1068(49.3 \%)$ \\
\hline Caucasian only & NA & NA & 524 & 573 & $1097(50.7 \%)$ \\
\hline Female & $372(73.4 \%)$ & $284(53.0 \%)$ & $329(64.0 \%)$ & $363(63.7 \%)$ & $1348(63.4 \%)$ \\
\hline \multicolumn{6}{|l|}{ Age (years) } \\
\hline$<45$ & $238(47.6 \%)$ & $278(55.6 \%)$ & $223(43.3 \%)$ & $218(39.2 \%)$ & $957(46.2 \%)$ \\
\hline $45-64$ & $209(41.8 \%)$ & $155(31.0 \%)$ & $214(41.6 \%)$ & $239(43.0 \%)$ & $817(39.5 \%)$ \\
\hline $65+$ & $53(10.6 \%)$ & $67(13.4 \%)$ & $78(15.2 \%)$ & $99(17.8 \%)$ & $297(14.3 \%)$ \\
\hline At least some college & $258(51.2 \%)$ & $347(64.5 \%)$ & $328(64.4 \%)$ & $490(87.2 \%)$ & $1423(67.4 \%)$ \\
\hline \multicolumn{6}{|l|}{ Knowledge of test type } \\
\hline Correct & $230(44.0 \%)$ & $232(42.6 \%)$ & $285(54.4 \%)$ & $259(45.2 \%)$ & $1006(46.5 \%)$ \\
\hline Incorrect/don’t know & $235(44.9 \%)$ & $284(52.1 \%)$ & $207(39.5 \%)$ & $298(52.0 \%)$ & $1024(47.3 \%)$ \\
\hline Missing & $58(11.1 \%)$ & $29(5.3 \%)$ & $32(6.1 \%)$ & $16(2.8 \%)$ & $135(6.2 \%)$ \\
\hline MOS General Health $^{a}$ & $61.4 \pm 22.7$ & $73.0 \pm 17.6$ & $59.1 \pm 25.0$ & $66.9 \pm 19.8$ & $65.3 \pm 22.0$ \\
\hline
\end{tabular}

\footnotetext{
${ }^{a}$ Scaled as 0 to 100 , where $100=$ perfect health; values are mean \pm standard deviations.
} 
Table 2

Percent accepting test by participant characteristics and type of test

\begin{tabular}{|c|c|c|c|c|}
\hline \multirow[b]{2}{*}{ Characteristic } & \multicolumn{2}{|c|}{ Genotypic } & \multicolumn{2}{|c|}{ Phenotypic } \\
\hline & $\begin{array}{l}\text { Percent } \\
\text { accepting }\end{array}$ & $P$ value ${ }^{a}$ & $\begin{array}{l}\text { Percent } \\
\text { accepting }\end{array}$ & $P$ value $^{a}$ \\
\hline \multicolumn{5}{|l|}{ Test considered } \\
\hline Genotypic & 55.9 & - & NA & - \\
\hline Phenotypic & NA & & 58.4 & \\
\hline Gender & & 0.98 & & 0.014 \\
\hline Male & 56.2 & & 53.9 & \\
\hline Female & 56.2 & & 61.7 & \\
\hline Age Group & & 0.014 & & 0.36 \\
\hline$<45$ & 51.7 & & 57.7 & \\
\hline $45-64$ & 61.3 & & 62.1 & \\
\hline $65+$ & 54.6 & & 57.2 & \\
\hline Race and field center & & 0.0002 & & $<0.0001$ \\
\hline UCI Caucasian & 63.5 & & 67.4 & \\
\hline UAB Caucasian & 57.8 & & 61.9 & \\
\hline UAB African American & 44.0 & & 49.4 & \\
\hline Howard African American & 56.5 & & 54.3 & \\
\hline Education & & 0.84 & & 0.011 \\
\hline High school or less & 55.7 & & 53.6 & \\
\hline Some college or more & 56.3 & & 61.9 & \\
\hline Knowledge of test type & & $<0.0001$ & & 0.034 \\
\hline Correct & 62.4 & & 57.6 & \\
\hline Incorrect/don’t know & 52.8 & & 61.1 & \\
\hline Missing & 29.4 & & 44.8 & \\
\hline
\end{tabular}

${ }^{a} P$-values based on chi-square tests are for the association between the participant characteristic and willingness to take the test.

examined and not found to be statistically significant at $P<$ 0.05 . Predictors of stated acceptance of any test were female versus male gender $(P=0.038)$, age between 45 and 64 years compared to younger persons $(P=0.031)$, and race and FC group $(P<0.0001)$. To examine the latter effect, three pairwise comparisons were performed. Within site, UAB Caucasians were more likely to state acceptance a $\mathrm{HH} /$ iron overload test than UAB African Americans (odds $=1.6595 \%$ CI: 1.27, 2.13). Within race, HU African Americans were more likely to state acceptance of $\mathrm{HH} /$ iron overload test compared to UAB African Americans (odds $=1.48 ; 95 \%$ CI: 1.14, 1.93), but Caucasians at $\mathrm{UCI}$ versus $\mathrm{UAB}$ were more similar in stated test acceptance (odds $=1.28 ; 95 \%$ CI: 0.99, 1.67). Finally, persons with higher self-rated general health perceptions were less likely to state acceptance of $\mathrm{HH} /$ iron overload screening than those reporting lower health ratings $(P=0.009)$.

Tables 4 and 5 present the percentages of respondents who endorsed each attitudinal item as a "very important" reason for their decision to accept or reject either phenotypic or ge-
Table 3

Adjusted odds of accepting an $\mathrm{HH} /$ iron overload test by type of test offered and participant characteristics

\begin{tabular}{lcr}
\hline \multicolumn{1}{c}{ Characteristic } & $\begin{array}{c}\text { Odds ratio }^{a} \\
(95 \% \mathrm{CI})\end{array}$ & $P$ value $^{b}$ \\
\hline Test & $0.85(0.71,1.02)$ & 0.078 \\
$\quad$ Genotypic vs. phenotypic & 0.031 \\
Gender & $1.23(1.02,1.49)$ & \\
$\quad$ Female vs. male & & 0.038 \\
Age group & $1.27(1.04,1.55)$ & \\
45-64 vs. $<45$ years & $0.98(0.75,1.29)$ & \\
$65+$ vs. $<45$ years &
\end{tabular}

Race and field center ${ }^{c}$

Caucasian vs. African Americans at UAB

$1.65(1.27,2.13)$

UCI vs. UAB Caucasians

$1.28(0.99,1.67)$

Howard vs. UAB African Americans

$1.48(1.14,1.93)$

Education

0.28

At least some college vs. high school or less

$1.12(0.91,1.37)$

MOS general health score (divided by 10)

$0.94(0.90,0.99)$

0.009

Knowledge of test type

0.034

Incorrect/don't know vs. correct

$0.59(0.38,0.92)$

Missing vs. correct

$0.86(0.71,1.03)$

${ }^{a}$ Odds ratios and $95 \%$ confidence intervals are adjusted for all variables shown in table.

${ }^{b} P$ values are for overall effects of characteristics adjusted for all variables shown in table.

${ }^{c}$ Race and Field Center were coded as 3 indicator variables, where UCI Caucasians served as the reference group.

notypic test, by race. Among acceptors, the most prevalent reasons cited were to gain knowledge about one's health $(81 \%$ overall), the potential usefulness of this knowledge to help family members $(71 \%)$, and a desire to know if they have iron problems or hemochromatosis (69\%). Relatively few acceptors were motivated either by knowing someone with $\mathrm{HH}$ or by suspicion that he/she had $\mathrm{HH}$. The most prevalent reasons for declining either test (Table 5) were a need to discuss the test with their primary care doctor ( $44 \%$ overall), a desire for more information (39\%), not having time (35\%), concerns about privacy (32\%), and a dislike of their having blood drawn (29\%). Reasons least frequently cited were not approving of aspects of $\mathrm{HH}$ testing, the possibility that more medical tests might be needed, and belief that the information might be disturbing to family members.

Among "acceptors" the proportions of African Americans and Caucasians in each testing group who cited each reason as "very important" were not statistically different. Among "decliners," African Americans offered a phenotypic test were more likely to want to speak with a doctor before being tested, to worry that information might not be kept private, and to not want to know if they had $\mathrm{HH}$ than those offered the genotypic test. 
Table 4

Reasons for accepting hemochromatosis phenotypic or genotypic test by race/ethnicity

\begin{tabular}{|c|c|c|c|c|c|}
\hline \multirow[b]{2}{*}{ Question: Would you like to have this test? } & \multicolumn{2}{|c|}{ African American ${ }^{b}$} & \multicolumn{2}{|c|}{ Caucasian $^{b}$} & \multirow[b]{2}{*}{ Overall } \\
\hline & $\begin{array}{c}\text { Phenotypic }^{a} \\
\%(N)\end{array}$ & $\begin{array}{c}\text { Genotypic } \\
\%(N)\end{array}$ & $\begin{array}{c}\text { Phenotypic } \\
\%(N)\end{array}$ & $\begin{array}{c}\text { Genotypic } \\
\%(N)\end{array}$ & \\
\hline I would like to know more about my health. & $82 \%(222)$ & $84 \%(225)$ & $80 \%(280)$ & $79 \%(266)$ & $81 \%(993)$ \\
\hline If I had hemochromatosis, knowing this might help my family members. & $74 \%(201)$ & $75 \%(197)$ & $69 \%(241)$ & $68 \%(230)$ & $71 \%(869)$ \\
\hline I want to know if I have iron problems / hemochromatosis. & $77 \%(210)$ & $72 \%(187)$ & $67 \%(236)$ & $60 \%(202)$ & $69 \%(835)$ \\
\hline I appreciate the chance to have a free medical test. & $55 \%(149)$ & $55 \%(147)$ & $59 \%(204)$ & $60 \%(202)$ & $58 \%(702)$ \\
\hline I think my doctor would recommend this test. & $43 \%(116)$ & $43 \%(112)$ & $38 \%(129)$ & $39 \%(128)$ & $41 \%(485)$ \\
\hline I have some symptoms that I would like to get checked. & $34 \%(82)$ & $36 \%(86)$ & $36 \%(118)$ & $34 \%(108)$ & $35 \%(394)$ \\
\hline I think I might have hemochromatosis. & $16 \%(36)$ & $20 \%(43)$ & $13 \%(44)$ & $15 \%(44)$ & $16 \%(167)$ \\
\hline I know someone who has hemochromatosis. & $8 \%(16)$ & $8 \%(15)$ & $12 \%(31)$ & $15 \%(30)$ & $11 \%(92)$ \\
\hline
\end{tabular}

a Percentages based on non-missing item response of "very important" as reason for accepting test.

${ }^{b}$ Proportions shown not statistically different by phenotypic and genotypic test at $P<0.05$.

Table 5

Reasons for declining test offered, by race/ethnicity ${ }^{a}$

\begin{tabular}{|c|c|c|c|c|c|}
\hline \multirow[b]{2}{*}{ Question: Would you like to have this test? } & \multicolumn{2}{|c|}{ African American } & \multicolumn{2}{|c|}{ Caucasian } & \multirow[b]{2}{*}{ Overall } \\
\hline & Phenotypic & Genotypic & Phenotypic & Genotypic \% $(N)$ & \\
\hline I would like to talk to my doctor before I receive this test. & $57 \%(128)$ & $44 \%(106)^{b}$ & $37 \%(66)$ & $35 \%(73)$ & $44 \%(373)$ \\
\hline I would like more information. & $46 \%(102)$ & $46 \%(108)$ & $31 \%(54)$ & $30 \%(62)$ & $39 \%(326)$ \\
\hline I don't have time today. & $27 \%(56)$ & $32 \%(73)$ & $39 \%(68)$ & $42 \%(87)$ & $35 \%(284)$ \\
\hline My information might not be kept private. & $41 \%(85)$ & $32 \%(76)^{c}$ & $22 \%(36)$ & $30 \%(61)$ & $32 \%(258)$ \\
\hline I don't like having my blood drawn. & $32 \%(64)$ & $36 \%(79)$ & $24 \%(42)$ & $23 \%(46)$ & $29 \%(231)$ \\
\hline It is unlikely that I have hemochromatosis. & $24 \%(51)$ & $26 \%(62)$ & $34 \%(57)$ & $30 \%(46)$ & $28 \%(230)$ \\
\hline I'm not sure if I need this test. & $25 \%(53)$ & $26 \%(59)$ & $32 \%(55)$ & $29 \%(58)$ & $28 \%(225)$ \\
\hline I don't want to participate in any blood test program. & $23 \%(49)$ & $27 \%(63)$ & $23 \%(40)$ & $17 \%(34)$ & $23 \%(186)$ \\
\hline I don't want to know if I have hemochromatosis. & $30 \%(63)$ & $21 \%(50)^{\mathrm{c}}$ & $13 \%(22)$ & $12 \%(24)$ & $20 \%(159)$ \\
\hline $\begin{array}{l}\text { There are things about testing for hemochromatosis that I do not } \\
\text { like or approve of. }\end{array}$ & $21 \%(43)$ & $26 \%(63)$ & $8 \%(13)$ & $13 \%(26)$ & $18 \%(145)$ \\
\hline I might need more medical tests. & $24 \%(50)$ & $21 \%(46)$ & $14 \%(22)$ & $12 \%(23)$ & $18 \%(141)$ \\
\hline $\begin{array}{l}\text { If I had hemochromatosis, the information might disturb my } \\
\text { family members. }\end{array}$ & $21 \%(44)$ & $19 \%(43)$ & $12 \%(20)$ & $9 \%(18)$ & $16 \%(125)$ \\
\hline
\end{tabular}

a Percentages based on non-missing item response of "very important" as reason for declining test.

${ }^{b} P<0.001$ for test of proportions by type of test.

${ }^{c} P<0.05$ for test of proportions by type of test.

Finally, approximately three-fourths of those who hypothetically accepted a genotypic test $(76.5 \%)$ and phenotypic test $(76.4 \%)$ were categorized as having enrolled in HEIRS to participate in $\mathrm{HH} /$ iron overload screening. In contrast, only $8.6 \%$ of decliners of either test enrolled.

\section{CONCLUSION}

We assessed willingness to undergo screening for $\mathrm{HH} /$ iron overload in a clinical setting based upon type of test offered and measured potential biases against genetic testing. We found only small differences in stated willingness to accept a genetic versus phenotypic testing for $\mathrm{HH}, 56 \%$ and $58 \%$ of study participants, respectively, agreed to be tested for $\mathrm{HH}$ with biochemical or genetic testing. Because a genetic test can identify people with no present iron overload but who may develop it in the future, it is encouraging that this testing modality appears to be as acceptable as conventional screening methods.

Adjusting for all covariates, African Americans living in the deep South were less likely to accept either test than Caucasians or African Americans living in the mid-Atlantic region. It was not feasible to broaden the design of this study so that the 
influence of region and race or ethnicity on test acceptability could be disentangled, the results suggest that willingness to accept medical testing in the circumstances presented may be influenced by local historical and cultural conditions and vary regionally. The notorious Tuskegee, Alabama United States Public Health Service research scandal may be an example of negative historical influence on trust in the medical system. ${ }^{36,37}$ More research is needed to test this hypothesis and to more fully explore how views toward testing reflect larger social processes.

Having a correct understanding of which hypothetical test was offered influenced willingness to accept a genotypic but not phenotypic test. Only $53 \%$ of those who did not recognize that the test described was a genetic test found this test acceptable as opposed to $62 \%$ of those who correctly reported that the test included genetic testing. This result suggests that confusion or lack of familiarity with the genetic testing makes people more hesitant about testing. This may be important to address in the design of population screening programs.

Screening programs may also need to be framed in a broader health perspective, rather than a disease-specific one. In this study, neither suspicion of having $\mathrm{HH}$ or iron overload, nor familiarity with this disease was an appreciable motivator for testing; it was a desire to know more about one's health that led to high acceptance. In fact, willingness to be screened for $\mathrm{HH}$ was influenced by perceived health status. Persons with lower perceived health were possibly more motivated to seek care or an explanation for their potential health problems, or alternatively, they may have been more familiar with medical tests.

For both types of tests, the largest correlates of acceptability were the level of understanding of the nature and purpose of the test, general interest in finding out about health problems, concerns about privacy, and impact on family members. Providing clear information about $\mathrm{HH}$ and addressing potential concerns with testing will be important if $\mathrm{HH}$ screening is to be successfully promoted in the population, as has been advocated. ${ }^{24,25,27}$

Our findings on overall acceptability of $\mathrm{HH}$ testing are generally consistent with those of Patch and colleagues ${ }^{38}$ who assessed acceptability of phenotypic and genotypic $\mathrm{HH}$ testing in a randomized screening study in the UK. They found no differences in iron overload/HH screening participation based on method, but observed that age, gender, and socioeconomic status were predictors of general acceptance. Our findings that approximately one-half of a diverse group of participants had a favorable view of $\mathrm{HH}$ testing is however lower than that reported by Hicken, ${ }^{39}$ who found quite high (94\%) acceptance in an older adult sample, with only $8 \%$ expressing some concern over testing. Whereas their sample was based on persons already enrolled in a clinical trial, our study randomized patients waiting to be seen for an unrelated reason in a primary care office, and involved reading a paragraph and answering a brief questionnaire, modeling how $\mathrm{HH}$ screening might be offered patients in primary care practices. We speculate that lower test acceptance might occur if subjects were approached in other settings (e.g., public health fairs) where it would not have im- plicit or explicit endorsement of the test by their physician, or in circumstances where a special clinic visit or site would be needed in order to obtain the test.

We found that concerns among the nearly half of the participants who did not want testing with either method included a desire to discuss $\mathrm{HH}$ testing with their physician or to have more information about the condition disease. Some also expressed concerns about privacy. African Americans more often had reservations relating to privacy and concerns about the impact on family relations.

As is often the case with clinical studies, the applicability of the results of this study are limited to patients seeking primary care services, and to the clinical sites studied. First, this study presented and tested a hypothetical scenario of $\mathrm{HH} /$ iron overload testing, but not the more direct behavior of test participation. However, we were able to record whether participants of this study actually enrolled in the HEIRS screening study and found that most (76\%) hypothetical test acceptors did join HEIRS, and most hypothetical test decliners did not (92\%). Thus, it appears that the expressed beliefs and attitudes toward $\mathrm{HH} /$ iron overload testing in this study demonstrate excellent predictive validity.

Another potential limitation is that despite efforts to recruit from a wide variety of clinical settings, participants in the study were more highly educated than the general population in their respective cities ${ }^{40}$; however, this bias may be reflective of the clinical populations that have insurance and seek care in ambulatory care settings. Whether individuals willing to take part in a research study represent a different or biased segment of the population is also of concern. The HEIRS Acceptability Study sought to limit this problem by assessing interest in genetic versus phenotypic testing in a primary care population not yet enrolled in the screening study. All were then offered entry into the larger, HEIRS study. In addition, results from this study in $\mathrm{HH}$ in which the treatment can be as simple and inexpensive as periodic phlebotomy, may not be generalizable to other predictive tests in which prevention and or treatment may be more difficult for both patients and physicians and less effective.

In conclusion, in this diverse sample of primary care patients, we did not find evidence that genetic testing for known $\mathrm{HH}$ mutations was less acceptable than phenotypic testing for blood iron levels. Within health care settings, patient education regarding the nature of test, the importance of disease detection, and the protection of privacy appear to be essential for achieving high rates of participation in either test.

\section{ACKNOWLEDGMENTS}

The HEIRS Study was initiated and funded by the National Heart, Lung, and Blood Institute, in conjunction with the National Human Genome Research Institute. The study is supported by contracts N01-HC05185 (University of Minnesota), N01-HC05186 (Howard University), N01-HC05188 (University of Alabama at Birmingham), N01-HC05189 (Kaiser Permanente Center for Health Research), N01-HC05190 (University of California, Irvine), N01-HC05191 (London Health 
Sciences Centre), and N01-HC05192 (Wake Forest University). Additional support was provided by the Howard University General Clinical Research Center (GCRC) grant, M01-RR10284, and the UCSD/UCI Satellite GCRC grant, M01-RR00827 (University of California, Irvine), sponsored by the National Center for Research Resources, National Institutes of Health. HEIRS Study investigators are listed at https://www.heirs-study.org/ PP_Policy.htm

The authors would like to acknowledge the following HEIRS field center staff for their additional participation and contributions to the Acceptability sub study: Mariko D. Brandon, B.A.; Jennifer A. Crabb, M.S.; Deborah Dixon; Dr. Bret Hicken; Sandi King, M.S.; Dr. Charles A. Rivers; Janice C. Ware assisted from the University of Alabama at Birmingham, Birmingham, AL; Jo Ann Baca; Thelma Narciso assisted from the University of California, Irvine, CA; Catherine U. Nwokolo; Iola Williams; Margaret Fadojutimi-Akinsiku; Sharmin Diaz; Angela S. Rock; Barbara W. Harrison assisted from the Howard University, Washington, D.C.; Andrea Ruggiero assisted from the Winston-Salem, NC Coordinating Center.

\section{References}

1. Guttmacher AE, Collins FS. Welcome to the genomic era. N Engl J Med 2003;349: 996-8.

2. Collins FS. A brief primer on genetic testing. Paper presented World Economic Forum, Jan 24. 2003 Porto Alegre Brazil. Available at: www.http//nhgri.nih.gov/ 10506784. Accessed January 2005.

3. Boyle P. Introduction to Genetic Grammar: Health, Illness, and the Human Genome Project. Hastings Center Report 1992;22:S1.

4. Hubbard R, Wald E. Exploding the Gene Myth: How Genetic Information Is Produced and Manipulated by Scientists, Physicians, Employers, Insurance Companies, Educators, and Law Enforcers. 1993;206 p. Boston: Beacon Press.

5. Wertz DC, Fletcher JC, eds. (1989) Ethics and Hum Genet: A Cross-cultural Perspective. 536 p. Berlin and New York: Springer-Verlag.

6. Bish A, Sutton S, Jacobs C, Levine S, Ramirez A, Hodgson S. No news is (not necessarily) good news: impact of preliminary results for BRCA1 mutation searches. Genet Med 2002;4:353-358.

7. Broadstock M, Michie S, Marteau T. Psychological consequences of predictive genetic testing: a systematic review. Eur J Hum Genet 2000;8:731-8.

8. Coyne JC, Kruus L, Racioppo M, Calzone KA, Armstrong K. What do ratings of cancer-specific distress mean among women with high risk of breast and ovarian cancer? Am J Med Genet 2003;116A:222-228.

9. Horowitz MJ, Field NP, Zanko A, Donnelly EF, Epstein C, Longo F. Psychological impact of news of genetic risk for Huntington disease. Am J Med Genet 2001;103: 88-92.

10. Bonadona V, Saltel P, Desseigne F, et al. Cancer patients who experienced diagnostic genetic testing for cancer susceptibility: reactions and behavior after the disclosure of a positive test result. Cancer Epidemiol Biomarkers Prev 2002;11:97-104.

11. Lodder L, Frets PG, Trijsburg RW, et al. Psychological impact of receiving a BRCA1/ BRCA2 test result. Am J Med Gen 2001;98:15-24.

12. Dorval M, Patenaude AF, Schneider KA, et al. Anticipated versus actual emotional reactions to disclosure of results of genetic tests for cancer susceptibility: Findings from p53 and BRCA1 testing programs. J Clin Oncol 2000;18:2135-2142.

13. Decruyenaere M, Evers-Kiebooms G, Cloostermans T, et al. Psychological distress in the 5-year period after predictive testing for Huntington's Disease. Eur J Hum Genet 2003;11:30-38.
14. Gordon C, Walpole I, Zubrick SR, Bower C. Population Screening for cystic fibrosis: knowledge and emotional consequences 18 months later. Am J Med Genet 2003; 120A:199-208.

15. van Maarle MC, Stouthard ME, Marang-van de Mheen PJ, Klazinga NS, Bonsel GH. How disturbing is it to be approached for a genetic cascade screening programme for familial hypercholesterolaemia? Psychological impact and screenees' views. Community Genet 2002;4:244-252.

16. Lerman C, Narod S, Schulman K, et al. BRCAl testing in families with hereditary breast-ovarian cancer. JAMA 1996;275:1885-1892.

17. Lerman C, Croyle R. Psychological issues in genetic testing for breast cancer susceptibility. Arch Intern Med 1994;154:609-616.

18. Schwartz MD, Peshkin BN, Hughes C, Main D, Isaacs C, Lerman C. Impact of BRCA1/BRCA2 mutation testing on psychologic distress in a clinic-based sample. J Clin Oncol 2002;20:514-20.

19. Croyle RT, Smith KR, Botkin JR, Baty B, Nash J. Psychological responses to BRCA1 mutation testing: Preliminary findings. Health Psychol 1997;16:63-72.

20. Lerman C, Hughes C, Lemon SJ, et al. What you don't know can hurt you: Adverse psychological effects in members of BRCA1-linked and BRCA2-linked families who decline genetic testing. J Clin Oncol 1998;16:1650-1654.

21. Meiser B, Butow P, Friedlander M, et al. Psychological impact of genetic testing for women for high risk breast cancer families. Eur J Cancer 2002;38:2025-2031.

22. Di Prospero LS, Seminsky M, Honeyford J, et al. Psychological issues following a positive result of genetic testing for BRCA1 and BRCA2 mutations: findings from a focus group and needs-assessment survey. CMAJ 2001;164:1005-1009.

23. Bacon BR. Hemochromatosis: diagnosis and management. Gastroenterology 2001; 120:718-725.

24. Barton JC, Acton RT. Population screening for hemochromatosis: has the time finally come? Curr Gastroenterol Rep 2000;2:18-26.

25. Dubois S, Kowdley KV. The importance of screening for hemochromatosis. Arch Intern Med 2003;163:2424-2426.

26. Niederau C, Fischer R, Purschel A, Stremmel W, Haussinger D, Strohmeyer G. Long-tern survival in patients with hereditary hemochromatosis. Gastroenterology 1996;110:1107-1119.

27. Motulsky AG, Beutler E. Population screening in hereditary hemochromatosis. Annu Rev Public Health 2000;21:65-79.

28. Feder JN, Gnirke A, Thomas W, et al. A novel MHC class I-like gene is mutated in patients with hereditary haemochromatosis. Nat Genet 1996;13:399-408.

29. Acton RT, Barton JC. Hereditary Hemochromatosis. In: Encyclopedia of Medical Genomics and Proteomics, Fuchs J, Podda M Eds, Marcel Dekker, Inc. New York, (In press, 2004).

30. Friedman LC, Webb JA, Richards CS, et al. Psychological impact of receiving negative BRCA1 mutation test results in Ashkenazim. Genet Med 1999;1:74-79.

31. Gason A, Aitken M, Metcalf S, Allen K, Delaycki M. Genetic susceptibility screening in schools: attitudeds of the school community towards hereditary haemochromatosis. Clin Genet 2004;67:166-174.

32. Corbie-Smith G, Thomas SB, Williams MV, Moody-Ayers S. Attitudes and beliefs of African Americans toward participation in medical research. J Gen Intern Med 1999;14:537-546.

33. McLaren CE, Barton JC, Adams PC, et al. Hemochromatosis and Iron Overload Screening (HEIRS) study design for an evaluation of 100,000 primary care-based adults. Am J Med Sci 2003;325:53-62.

34. Ware Jr. JE, Sherbourne CD. The MOS 36-item short-form health survey (SF-36). I. Conceptual framework and item selection. Med Care 1992;30:473-483.

35. McHorney CA, Ware Jr. JE, Lu JF, Sherbourne CD. The MOS 36-item Short-Form Health Survey (SF-36): III. Tests of data quality, scaling assumptions, and reliability across diverse patient groups. Med Care 1994;32:40-66.

36. White RM. Unraveling the Tuskegee Study of Untreated Syphilis. Arch Intern Med 2000;160:585-598.

37. White RM. Sociocultural Issues in Clinical Research: Unraveling the Tuskegee Syphilis Study. Arthritis \& Rheumatism 2002;47:456-458.

38. Patch C, Roderick P, Rosenberg W. Genetic screening for Hemochromatosis is no less acceptable than biochemical screening. Am J Human Gent 2003;735:417.

39. Hicken B, Calhoun DC, Tucker DC. Genetic testing for hemochromatosis: Attitudes and acceptability among young and older adults. Genetic Testing 2003;7:235-239.

40. U.S. Census Bureau; Census 2000, Summary File 1 (SF 1) and Summary File 3 (SF 3); generated by Shellie Ellis; using American FactFinder; Available at: http:// factfinder.census.gov. Accessed May 22005. 